\title{
Reasons for and against receiving influenza vaccination in a working age population in Japan: a national cross-sectional study
}

Tsubasa Iwasa ${ }^{1}$ and Koji Wada ${ }^{2^{*}}$

\begin{abstract}
Background: To improve influenza vaccination coverage in the working age population, it is necessary to understand the current status and awareness of influenza vaccination. This study aimed to determine influenza vaccination coverage in Japan and reasons for receiving the vaccine or not.

Methods: An anonymous internet-based survey was performed in September 2011. Our target study size was 3,000 participants between 20 and 69 years of age, with approximately 300 men and 300 women in each of five age groups (20-29, 30-39, 40-49, 50-59, and 60-69). We asked the history of influenza vaccine uptake in the previous year, and reasons for having vaccination or not.

Results: There were 3,129 respondents, of whom $24.2 \%$ of males and $27.6 \%$ of females received influenza vaccination between October 2010 and March 2011. Among those who were vaccinated, the main reasons for receiving the influenza vaccine were "Wanted to avoid becoming infected with influenza virus" (males: 84.0\%; females: $82.6 \%$ ) and "Even if infected with influenza, wanted to prevent the symptoms from becoming serious" (males: 60.7\%; females: 66.4\%). Among those not vaccinated, the most frequent reasons for not receiving the influenza vaccine included "No time to visit a medical institution" (males: 32.0\%; females: $22.4 \%$ ) and "Unlikely to become infected with influenza" (males: 25.1\%; females: 22.7\%).

Conclusions: The reasons for receiving the influenza vaccine varied between age groups and between sexes. To heighten awareness of influenza vaccination among unvaccinated working age participants, different intervention approaches according to sex and age group may be necessary.
\end{abstract}

Keywords: Influenza vaccination, Attitude, General population, Japan

\section{Background}

Influenza vaccination is an effective preventive measure [1], and is recommended for all individuals 6 months of age or older in the United States [2]. Although influenza vaccination of healthy working adults may not be costsaving [3], influenza vaccination can reduce the proportion of people developing influenza-like illness, the number of lost work days, and physician visits during the influenza epidemic season [4]. In the United States, where adults are encouraged to receive influenza vaccination, influenza vaccination coverage was $35.8 \%$ for individuals $18-49$ years old and $51.0 \%$ for those 50-64 years old [5]. Influenza

\footnotetext{
* Correspondence: kwada-sgy@umin.ac.jp

${ }^{2}$ Department of Public Health, Kitasato University School of Medicine, 1-15-1 Kitasato, Minami-ku, Sagamihara, Kanagawa 252-0374, Japan

Full list of author information is available at the end of the article
}

vaccination among working age Japanese people is also optional as in the United States and whether to be vaccinated or not is left to the individual. Influenza vaccination coverage in the working population of Japan [6] was approximately $30 \%$ before the influenza A (H1N1) pandemic in 2009.

Increasing uptake of influenza vaccination is an important issue to be addressed worldwide [7-9]. To increase influenza vaccination coverage, it is important to understand the motivation for and barriers against influenza vaccination uptake. Reasons for being vaccinated have been reported in previous studies, and include: the presence of chronic disease [10,11]; perceived susceptibility to influenza with a desire to avoid contracting seasonal influenza; knowing someone who became ill from seasonal influenza; protecting oneself from illness; protecting close

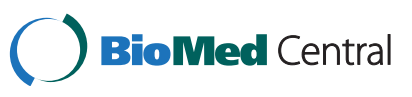


relatives by receiving the vaccine $[12,13]$; reducing transmission to others [14]; being advised by a family doctor/ nurse to be vaccinated $[15,16]$; having knowledge that influenza is a serious illness [16,17]; and having knowledge of the national vaccination strategy [18]. These reasons varied by age and sex. Reasons for not being vaccinated against influenza include: believing that influenza vaccine was unnecessary $[19,20]$; being concerned about side effects of vaccination $[12,14,19]$; believing oneself to be unlikely to contract influenza [16,17]; being unconcerned about influenza [21]; and lack of convenient access to vaccination [22].

We consider it necessary to understand the current status and awareness of influenza vaccination in order to promote influenza vaccination uptake among working age people in Japan. The aim of this study was to investigate the history of influenza vaccination in 2010 in Japanese men and women of working age (20-69 years), and to identify reasons for receiving or not receiving this vaccine.

\section{Methods}

This study recruited 3,000 Japanese individuals aged 2069 years who were registered by a web survey company in September 2011. People who were interested in taking part in a survey, with financial incentives for responding, registered voluntarily on the company website. The company randomly selected 7,937 subjects from a total of 1.60 million registrants based on the company protocol considering the estimated response rate to recruit 3000 participants within a week, and sent out invitations by e-mail to take part in the survey.

With regard to sample size, we determined 267 sample size needed per each gender (men and women) and 10 year age band $(20-29,30-39,40-49,50-59$, and $60-$ 69). based on the assumption as follows: confidence level $95 \%$, margin of error 6 , and 7 million population based on the Japanese population structure. Then, we decided to recruit 300 sample size in each gender and 10 year age band as a stratified random sampling method. The company ceased recruitment in each category once the desired number agreed to participate. We obtained agreement and consent of all subjects for participation in the survey when they completed their answers.

This study was approved by the Kitasato University School of Medicine Ethics Committee prior to implementation.

We asked participants if they had received an influenza vaccination in the period from October 2010 to March 2011, offering three possible responses: yes, no, and do not remember. Questions were formulated after reviewing previous studies [12-22] and are shown in Table 1.

\section{Statistical analysis}

We conducted univariate analysis using Pearson's chisquared test to examine the potential relationships

\section{Table 1 Questions asked in this study}

I. Of those who had received an influenza vaccination, we inquired about reasons for receiving vaccination (allowing each respondent to give as many answers as they wished

1. Wanted to avoid becoming infected with influenza virus.

2. Even if infected with influenza, wanted to prevent the symptoms from becoming serious.

3. Living with family members at high risk of influenza becoming serious such as children, the elderly or pregnant women.

4. Received financial assistance for vaccination.

5. At high risk of becoming infected with influenza.

6. Employer ordered the vaccination.

7. At high risk of influenza symptoms becoming serious if infected.

8. Family, friends, and acquaintances recommended it.

9. Family doctor recommended it.

II. Of those who had not received an influenza vaccination, we asked the reasons for not being vaccinated (multiple choices were allowed).

1. No time to visit a medical institution.

2. Believed oneself unlikely to be infected with influenza.

3. Could not afford vaccination.

4. Lack of confidence that influenza vaccinations are effective.

5. Believed that disease would not likely become severe even if infected with influenza.

6. Concerned about adverse reactions that might occur with vaccinations

7. Dislike of injections.

8. Lack of knowledge about where to be vaccinated.

9. Prior experience of an adverse reaction after being vaccinated for influenza or another disease.

between men and women in the rate of vaccination uptake. All analyses were performed using IBM SPSS Statistics v. 19 (IBM Corp, Armonk, NY, USA), with statistical significance set at $\mathrm{p}<0.05$.

\section{Results}

A total of 3,129 participants participated in the survey (response rate:39.4\%). We recruited approximately equal numbers of males and females, and participants were relatively equally distributed among the age groups (Table 2). With respect to influenza vaccination, $24.2 \%$ of males and $27.7 \%$ of females had been vaccinated against influenza (Table 3). A slightly higher proportion of females were vaccinated than males, but there were no significant differences in the vaccination rates in any age group. The age group with the highest proportion of vaccination was aged $60-69$, with $28.3 \%$ of males and $30.4 \%$ of females in this age group vaccinated.

The reported reasons for receiving influenza vaccination are shown in Table 4. The major reasons in descending order were "Wanted to avoid becoming infected with influenza virus" (84.0\% of males and $82.6 \%$ of females 
Table 2 Characteristics of participants

\begin{tabular}{lcc}
\hline & $\mathbf{N}=\mathbf{3 1 2 9}$ & $\mathbf{( \% )}$ \\
\hline Sex & & \\
Male & 1,572 & $(50.2)$ \\
Female & 1,557 & $(49.8)$ \\
Age (years) & & \\
$20-29$ & 510 & $(16.3)$ \\
$30-39$ & 659 & $(21.1)$ \\
$40-49$ & 647 & $(20.7)$ \\
$50-59$ & 601 & $(19.2)$ \\
$60-69$ & 712 & $(22.8)$ \\
\hline
\end{tabular}

vaccinated); "Even if infected with influenza, wanted to prevent the symptoms from becoming serious" (60.7\% of males and $66.4 \%$ of females); "Living with family members at high risk of influenza becoming serious, such as children, the elderly or pregnant women" (18.4\% of males and $31.5 \%$ of females); and "Received financial assistance for vaccination" (18.6\% of males and $21.0 \%$ of females). A large proportion of females aged 30-39 years reported "Living with family members at high risk of influenza becoming serious, such as children, the elderly or pregnant women" (52.8\%), and many males and females aged 20-29 years gave the response that "Family, friends, and acquaintances recommended it" (20.4\% of males and $16.5 \%$ of females).

Table 5 shows the reported reasons for not being vaccinated against influenza. In males, "No time to visit a medical institution" was the most frequent reason among those aged 20-59 (32.3-42.8\%), whereas "Believed oneself unlikely be infected with influenza" was the most frequent reason among those aged 60-69 (39.2\%). In contrast, among females, the most frequent reasons for not being vaccinated were "No time to visit a medical institution" in those aged 20-29 (33.9\%), "Could not afford vaccination " in those aged 30-39 (35.2\%) and 40-49 (28.6\%), "Concern about adverse reactions that might occur with vaccinations" in those 50-59 (22.7\%),

Table 3 Vaccination coverage in the year up to September 2011 by sex and age (\%)

\begin{tabular}{lccc}
\hline $\begin{array}{l}\text { Age } \\
\text { group } \\
\text { (years) }\end{array}$ & $\begin{array}{c}\text { Male } \\
\text { vaccinated } \\
\text { (\% total age group) }\end{array}$ & $\begin{array}{c}\text { Female } \\
\text { Number } \\
\text { (\% of total age group) }\end{array}$ & p-value \\
\hline $20-29$ & $54 / 262(20.6)$ & $68 / 248(27.4)$ & 0.19 \\
$30-39$ & $80 / 332(24.1)$ & $93 / 327(28.4)$ & 0.35 \\
$40-49$ & $79 / 326(24.2)$ & $75 / 321(23.4)$ & 0.86 \\
$50-59$ & $68 / 302(22.5)$ & $85 / 299(28.4)$ & 0.21 \\
$60-69$ & $99 / 350(28.3)$ & $110 / 362(30.4)$ & 0.69 \\
Total & $380 / 1572(24.2)$ & $431 / 1557(27.7)$ & 0.90 \\
\hline
\end{tabular}

and "Lack of confidence that influenza vaccinations are effective" in those aged 60-69 (31.0\%).

\section{Discussion}

This study aimed to determine the current status of influenza vaccination uptake in a working population (20-69 years) in Japan, and reasons for this population receiving or not receiving the vaccine. Overall, the most frequent reasons for receiving the vaccine were the desire to avoid infection with the influenza virus, and the desire to prevent symptoms becoming serious if already infected with the virus. The primary reasons for not receiving the vaccine included no time to visit a medical institution, the belief of being unlikely to become infected with influenza, and the inability to afford the vaccine, although there were variations in reasons according to sex and age.

Prevention of the onset of influenza and preventing influenza symptoms from becoming serious were the two major reasons given by individuals who received influenza vaccination. The influenza vaccine provides modest protection against the onset of influenza, with the efficacy rate reportedly being 51-67\% in individuals aged 18-65 years [23]. Furthermore, 33 healthy adults need to be vaccinated to avoid one incurring influenza symptoms [24]. Twenty one percent of respondents chose "Lack of confidence that influenza vaccinations are effective" as a reason not to be vaccinated. They may be rightly critical of vaccine efficacy because of possible mismatching between circulating virus strains and the strains in the vaccine itself. The limitations of vaccine efficacy should be communicated to the general public, to maintain realistic expectations of the vaccine [15] .

The reasons for receiving influenza vaccination varied according to sex and age. Among those aged 3039 years, a substantial proportion reported that they were vaccinated because they were living with family members at high risk of influenza becoming serious, such as children, the elderly, or pregnant women. Maternal influenza immunization is a strategy with substantial benefits for both mothers and infants [25], reflecting the fact that people aged 30-39 are commonly rearing children. Among those aged 20-29 years, a relatively higher proportion cited recommendations from family, friends, or acquaintances as the reason for accepting the influenza vaccine. These results suggest that educational messages should aim to address a wide range of possible concerns, and to improve targeted outreach to specific groups of workers.

The reasons for not receiving influenza vaccination also varied according to sex and age group. Among men aged 20-59 years, the most frequent reason for not receiving the vaccine was lack of time to visit a medical institution. A lack of time has also been cited as a major reason for healthcare workers not receiving the influenza 
Table 4 Reasons for having influenza vaccination(\%)

\begin{tabular}{|c|c|c|c|c|c|c|c|c|c|c|c|c|}
\hline \multirow[b]{2}{*}{ Choices } & \multicolumn{6}{|c|}{ Male } & \multicolumn{6}{|c|}{ Female } \\
\hline & $\begin{array}{c}\text { Total } \\
(n=380)\end{array}$ & $\begin{array}{c}20-29 \\
(n=54)\end{array}$ & $\begin{array}{c}30-39 \\
(n=80)\end{array}$ & $\begin{array}{c}40-49 \\
(n=79)\end{array}$ & $\begin{array}{c}50-59 \\
(n=68)\end{array}$ & $\begin{array}{c}60-69 \\
(n=99)\end{array}$ & $\begin{array}{c}\text { Total } \\
(n=431)\end{array}$ & $\begin{array}{c}20-29 \\
(n=68)\end{array}$ & $\begin{array}{c}30-39 \\
(n=93)\end{array}$ & $\begin{array}{c}40-49 \\
(n=75)\end{array}$ & $\begin{array}{c}50-59 \\
(n=85)\end{array}$ & $\begin{array}{c}60-69 \\
(n=110) \\
\end{array}$ \\
\hline \multirow{2}{*}{$\begin{array}{l}\text { Wanted to avoid becoming infected } \\
\text { with influenza virus. }\end{array}$} & 84.0 & 83.8 & 87.8 & 88.5 & 84.6 & 77.1 & 82.6 & 84.0 & 84.2 & 84.5 & 80.3 & 80.9 \\
\hline & $(80.3-87.7)$ & (74.0-93.6) & $(80.6-95.0)$ & $(81.5-95.5)$ & $(76.0-93.2)$ & $(68.8-85.4)$ & $(79.0-86.2)$ & $(75.3-92.7)$ & (76.8-91.6) & $(76.3-92.7)$ & (71.8-88.8) & $(73.6-88.2)$ \\
\hline \multirow{2}{*}{$\begin{array}{l}\text { Even if infected with influenza, wanted } \\
\text { to prevent the symptoms from } \\
\text { becoming serious. }\end{array}$} & 60.7 & 52.2 & 61.3 & 66.5 & 62.3 & 58.9 & 66.4 & 40.0 & 71.1 & 73.2 & 72.4 & 69.5 \\
\hline & $(55.8-65.6)$ & $(38.9-65.5)$ & (50.6-72.0) & $(56.1-76.9)$ & (50.8-73.8) & $(49.2-68.6)$ & $(61.9-70.9)$ & $(28.4-51.6)$ & $(61.9-80.3)$ & $(63.2-83.2)$ & $(62.9-81.9)$ & $(60.9-78.1)$ \\
\hline \multirow{2}{*}{$\begin{array}{l}\text { Living with family members at high } \\
\text { risk of influenza becoming serious }\end{array}$} & 18.4 & 5.8 & 33.7 & 27.3 & 15.1 & 7.8 & 31.5 & 21.1 & 52.8 & 38.3 & 25.2 & 20.3 \\
\hline & $(14.5-22.3)$ & $(0.0-12.0)$ & $(23.3-44.1)$ & $(17.5-37.1)$ & $(6.6-23.6)$ & $(2.5-13.1)$ & $(27.1-35.9)$ & $(11.4-30.8)$ & $(42.7-62.9)$ & $(27.3-49.3)$ & $(16.0-34.4)$ & $(12.8-27.8)$ \\
\hline \multirow{2}{*}{$\begin{array}{l}\text { Received financial assistance } \\
\text { for vaccination. }\end{array}$} & 18.6 & 3.6 & 22.3 & 27.9 & 15.9 & 18.3 & 21.0 & 13.3 & 21.5 & 23.4 & 22.3 & 22.7 \\
\hline & $(14.7-22.5)$ & $(0.0-8.6)$ & $(13.2-31.4)$ & $(18.0-37.8)$ & $(7.2-24.6)$ & $(10.7-25.9)$ & $(17.2-24.8)$ & $(5.2-21.4)$ & $(13.2-29.8)$ & $(13.8-33.0)$ & $(13.5-31.1)$ & $(14.9-30.5)$ \\
\hline \multirow{2}{*}{$\begin{array}{l}\text { At high risk of becoming infected } \\
\text { with influenza. }\end{array}$} & 13.1 & 16.1 & 19.0 & 15.2 & 7.7 & 8.6 & 12.6 & 13.8 & 13.2 & 8.9 & 14.6 & 12.2 \\
\hline & $(8.3-14.7)$ & $(6.3-25.9)$ & $(10.4-27.6)$ & $(7.3-23.1)$ & $(1.4-14.0)$ & $(3.1-14.1)$ & $(9.5-15.7)$ & $(5.6-22.0)$ & $(6.3-20.1)$ & $(2.5-15.3)$ & $(7.1-22.1)$ & $(6.1-18.3)$ \\
\hline \multirow[t]{2}{*}{ Employer ordered the vaccination } & 13.9 & 16.9 & 16.9 & 16.6 & 13.7 & 7.8 & 11.1 & 22.3 & 16.2 & 9.5 & 9.8 & 2.0 \\
\hline & $(10.4-17.4)$ & $(6.9-26.9)$ & $(8.7-25.1)$ & $(8.4-24.8)$ & $(5.5-21.9)$ & $(2.5-13.1)$ & $(8.1-14.1)$ & $(12.4-32.2)$ & $(8.7-23.7)$ & $(2.9-16.1)$ & $(3.5-16.1)$ & $(0.0-4.6)$ \\
\hline \multirow{2}{*}{$\begin{array}{l}\text { At high risk of influenza symptoms } \\
\text { becoming serious if infected. }\end{array}$} & 11.5 & 7.6 & 11.1 & 10.4 & 10.5 & 15.7 & 11.2 & 6.8 & 6.4 & 5.7 & 15.7 & 18.0 \\
\hline & $(8.3-14.7)$ & $(0.5-14.7)$ & $(4.2-18.0)$ & $(3.7-17.1)$ & $(3.2-17.8)$ & $(8.5-22.9)$ & $(8.2-14.2)$ & $(0.8-12.8)$ & $(1.4-11.4)$ & $(0.5-10.9)$ & $(8.0-23.4)$ & $(10.8-25.2)$ \\
\hline \multirow{2}{*}{$\begin{array}{l}\text { Family, friends, and acquaintances } \\
\text { recommended it. }\end{array}$} & 8.9 & 20.4 & 5.0 & 9.6 & 5.6 & 7.4 & 11.4 & 16.5 & 8.0 & 4.9 & 7.4 & 18.8 \\
\hline & $(6.0-11.8)$ & $(9.7-31.1)$ & $(0.2-9.8)$ & $(3.1-16.1)$ & $(0.1-11.1)$ & $(2.2-12.6)$ & $(8.4-14.4)$ & $(7.7-25.3)$ & $(2.5-13.5)$ & $(0.0-9.8)$ & $(1.8-13.0)$ & $(11.5-26.1)$ \\
\hline \multirow[t]{2}{*}{ Family doctor recommended it. } & 7.9 & 3.3 & 5.7 & 2.8 & 6.2 & 17.6 & 6.8 & 1.4 & 2.0 & 3.0 & 7.3 & 16.5 \\
\hline & $(5.2-10.6)$ & $(0.0-8.1)$ & $(0.6-10.8)$ & $(0.0-6.4)$ & $(0.5-11.9)$ & $(10.1-25.1)$ & $(4.4-9.2)$ & $(0.0-4.2)$ & $(0.0-4.8)$ & $(0.0-6.9)$ & $(1.8-12.8)$ & $(9.6-23.4)$ \\
\hline
\end{tabular}


Table 5 Reasons for not having influenza vaccination (\%)

\begin{tabular}{|c|c|c|c|c|c|c|c|c|c|c|c|c|}
\hline \multirow{3}{*}{ Choices } & \multicolumn{6}{|c|}{ Male } & \multicolumn{6}{|c|}{ Female } \\
\hline & Total & $20-29$ & $30-39$ & $40-49$ & $50-59$ & $60-69$ & Total & $20-29$ & $30-39$ & $40-49$ & $50-59$ & $60-69$ \\
\hline & $(n=1143)$ & $(n=197)$ & $(n=242)$ & $(n=231)$ & $(n=226)$ & $(n=247)$ & $(n=1113)$ & $(n=174)$ & $(n=231)$ & $(n=245)$ & $(n=213)$ & $(n=250)$ \\
\hline \multirow[t]{2}{*}{ No time to visit a medical institution. } & 32.0 & 42.8 & 33.7 & 36.6 & 32.3 & 17.3 & 22.4 & 33.9 & 23.5 & 25.9 & 21.0 & 11.1 \\
\hline & $(29.3-34.7)$ & $(35.9-49.7)$ & $(27.7-39.7)$ & $(30.4-42.8)$ & $(26.2-38.4)$ & $(12.6-22.0)$ & $(20.0-24.8)$ & $(26.9-40.9)$ & $(18.0-29.0)$ & $(20.4-31.4)$ & $(15.5-26.5)$ & $(7.2-15.0)$ \\
\hline \multirow{2}{*}{$\begin{array}{l}\text { Believed oneself unlikely to be infected } \\
\text { with influenza }\end{array}$} & 25.1 & 26.1 & 15.3 & 19.5 & 25.1 & 39.2 & 22.7 & 24.8 & 22.4 & 19.8 & 19.3 & 27.1 \\
\hline & $(22.6-27.6)$ & $(20.0-32.2)$ & $(10.8-19.8)$ & $(14.4-24.6)$ & $(19.4-30.8)$ & $(33.1-45.3)$ & $(20.2-25.2)$ & $(18.4-31.2)$ & $(17.0-27.8)$ & $(14.8-24.8)$ & $(14.0-24.6)$ & $(21.6-32.6)$ \\
\hline \multirow[t]{2}{*}{ Could not afford vaccination. } & 20.1 & 22.7 & 19.2 & 26.7 & 20.2 & 12.4 & 23.8 & 28.4 & 35.2 & 28.6 & 18.2 & 10.4 \\
\hline & $(17.8-22.4)$ & $(16.9-28.5)$ & $(14.2-24.2)$ & $(21.0-32.4)$ & $(15.0-25.4)$ & $(8.3-16.5)$ & $(21.3-26.3)$ & $(21.7-35.1)$ & $(29.0-41.4)$ & $(22.9-34.3)$ & $(13.0-23.4)$ & $(6.6-14.2)$ \\
\hline \multirow{2}{*}{$\begin{array}{l}\text { Lack of confidence that influenza } \\
\text { vaccinations are effective }\end{array}$} & 19.0 & 7.5 & 20.0 & 21.4 & 18.9 & 24.9 & 22.2 & 10.5 & 20.4 & 23.3 & 22.0 & 31.0 \\
\hline & $(16.7-21.3)$ & $(3.8-11.2)$ & $(15.0-25.0)$ & $(16.1-26.7)$ & $(13.8-24.0)$ & $(19.5-30.3)$ & $(19.8-24.6)$ & $(5.9-15.1)$ & $(15.2-25.6)$ & $(18.0-28.6)$ & $(16.4-27.6)$ & $(25.3-36.7)$ \\
\hline \multirow{2}{*}{$\begin{array}{l}\text { Believed that disease would not likely become } \\
\text { severe even if infected with influenza }\end{array}$} & 19.3 & 15.2 & 13.6 & 17.0 & 19.0 & 30.6 & 17.5 & 14.3 & 14.4 & 17.0 & 22.0 & 19.4 \\
\hline & $(17.0-21.6)$ & $(10.2-20.2)$ & $(9.3-17.9)$ & $(12.2-21.8)$ & $(13.9-24.1)$ & $(24.9-36.3)$ & $(15.3-19.7)$ & $(9.1-19.5)$ & $(9.9-18.9)$ & $(12.3-21.7)$ & $(16.4-27.6)$ & $(14.5-24.3)$ \\
\hline \multirow{2}{*}{$\begin{array}{l}\text { Concerned about adverse reactions that } \\
\text { might occur with vaccinations }\end{array}$} & 12.3 & 10.1 & 11.6 & 12.3 & 11.6 & 15.6 & 18.0 & 8.7 & 11.9 & 15.5 & 22.7 & 28.5 \\
\hline & $(10.4-14.2)$ & (5.9-14.3) & $(7.6-15.6)$ & $(8.1-16.5)$ & $(7.4-15.8)$ & $(11.1-20.1)$ & $(15.7-20.3)$ & $(4.5-12.9)$ & $(7.7-16.1)$ & $(11.0-20.0)$ & $(17.1-28.3)$ & $(22.9-34.1)$ \\
\hline \multirow[t]{2}{*}{ Dislike of injections } & 13.9 & 13.5 & 16.3 & 15.9 & 10.7 & 12.8 & 14.1 & 19.2 & 12.9 & 13.2 & 11.1 & 15.1 \\
\hline & $(11.9-15.9)$ & $(8.7-18.3)$ & $(11.6-21.0)$ & $(11.2-20.6)$ & $(6.7-14.7)$ & $(8.6-17.0)$ & $(12.1-16.1)$ & $(13.3-25.1)$ & $(8.6-17.2)$ & $(9.0-17.4)$ & $(6.9-15.3)$ & $(10.7-19.5)$ \\
\hline \multirow[t]{2}{*}{ Lack of knowledge about where to be vaccinated } & 6.1 & 9.1 & 6.5 & 3.3 & 5.6 & 6.6 & 3.4 & 8.0 & 5.2 & 1.8 & 1.0 & 2.1 \\
\hline & $(4.7-7.5)$ & $(5.1-13.1)$ & $(3.4-9.6)$ & $(1.0-5.6)$ & $(2.6-8.6)$ & $(3.5-9.7)$ & $(2.3-4.5)$ & $(4.0-12.0)$ & $(2.3-8.1)$ & $(0.1-3.5)$ & $(0.0-2.3)$ & $(0.3-3.9)$ \\
\hline \multirow{2}{*}{$\begin{array}{l}\text { Prior experience of an adverse reaction after } \\
\text { being vaccinated for influenza or another disease }\end{array}$} & 2.1 & 1.4 & 2.6 & 1.7 & 3.1 & 1.7 & 3.6 & 2.0 & 3.2 & 5.1 & 3.5 & 3.9 \\
\hline & $(1.3-2.9)$ & $(0.0-3.0)$ & $(0.6-4.6)$ & $(0.0-3.4)$ & $(0.8-5.4)$ & $(0.1-3.3)$ & $(2.5-4.7)$ & $(0.0-4.1)$ & $(0.9-5.5)$ & $(2.3-7.9)$ & $(1.0-6.0)$ & $(1.5-6.3)$ \\
\hline
\end{tabular}


vaccine [22]. There appear to be various misconceptions that stop people from perceiving vaccination as an important measure and one that deserves priority over other matters in their daily lives. There have been some measures that can ensure access to vaccination such as providing vaccination in pharmacies [26], and an incentive for vaccination, an intensified advertising campaign, and offering a choice of influenza vaccines can improve vaccination rates in the workplace [27]. Among men aged 60-69 years, the main reasons for not being vaccinated were the belief that they would not be infected with the influenza virus and that the disease would not become severe[28]. In Japan, influenza vaccination is recommended for people 65 years of age or older, and some local governments are providing financial support for vaccination [29]. Although men aged 60-69 may believe that they will not be infected or become seriously ill with influenza based on their experience, they should be given accurate information about the risk of infection, which increases with age.

The reasons for not receiving influenza vaccination varied more widely according to age among women than among men. The most frequent reason for not being vaccinated was lack of time to visit a medical institution in women aged 20-29, not being able to afford vaccination in those aged 30-49[30], concerns about adverse reactions in those aged 50-59, and doubts about vaccine efficacy in those aged 60-69. The avoidance of influenza vaccination among women aged 50-69 may be attributable to unfavorable views related to changes in influenza vaccination policy as a result of severe side effects and lawsuit judgments for compensation at the time their children were vaccinated [31]. If these women retain negative impressions of influenza vaccination after reaching the age of 65 when vaccination is recommended, it may be difficult to increase the influenza vaccination rate in this age group.

This study was limited because all study participants were internet users, thus its generalizability to the wider population in Japan may be restricted. It is possible that there are differences in educational status and income between internet users and non-users. In particular, internet users aged 60 or older may be better at assimilating information than are the general population. Another limitation is that because each individual chose multiple choices for questionnaire responses, and choices were not independent, we were not able to apply chi-square analysis or other statistical analysis to determine the differences according to sex and age.

\section{Conclusions}

This study suggests that the reasons for not accepting influenza vaccination vary according to sex and age in the Japanese working age population. We recommend using different education and intervention approaches according to sex and age to increase awareness of influenza vaccination among unvaccinated participants.

\section{Competing interests}

The authors declare that they have no competing interests.

\section{Authors' contributions}

KW conceived and implemented the study. TI and KW contributed equally to writing and revising the manuscript as the first author. All authors read and approved the final manuscript.

\section{Acknowledgments}

This work was supported by a Grant-in-Aid for Young Scientists (B) (23790705) from the Ministry of Education, Culture, Sports, Science and Technology, Japan and partly funded by a Health Labour Sciences Research Grant from the Ministry of Health, Labour, and Welfare, Japan. The funding bodies had no role in study design, data collection and analysis, decision to publish, or preparation of the manuscript.

\section{Author details}

${ }^{1}$ Saiwai Public Health Center, Kawasaki, 1-11-1 Todehonmachi, Saiwai-ku Kawasaki, Kanagawa 212-8570, Japan. ²Department of Public Health, Kitasato University School of Medicine, 1-15-1 Kitasato, Minami-ku, Sagamihara, Kanagawa 252-0374, Japan.

Received: 24 December 2012 Accepted: 9 July 2013

Published: 12 July 2013

\section{References}

1. Reichert TA, Sugaya N, Fedson DS, Glezen WP, Simonsen L, Tashiro M: The Japanese experience with vaccinating schoolchildren against influenza. N Engl J Med 2001, 344(12):889-896.

2. Practices ACol: Recommended adult immunization schedule: United States, 2012 (1). Ann Intern Med 2012, 156(3):211-217.

3. Nichol KL: Cost-benefit analysis of a strategy to vaccinate healthy working adults against influenza. Arch Intern Med 2001, 161(5):749-759.

4. Bridges CB, Thompson WW, Meltzer MI, Reeve GR, Talamonti WJ, Cox NJ, Lilac HA, Hall H, Klimov A, Fukuda K: Effectiveness and cost-benefit of influenza vaccination of healthy working adults: A randomized controlled trial. JAMA 2000, 284(13):1655-1663.

5. Centers for Disease Control and Prevention: Flu Vaccination Coverage United States, 2011-12 Influenza Season. 2012. Available at http://www.cdc.gov/flu/ professionals/vaccination/nfs-survey-march2012.htm.

6. Nobuhara $\mathrm{H}$, Watanabe $\mathrm{Y}$, Miura $\mathrm{Y}, \mathrm{K}$ N: Prediction of influenza vaccination uptake in Japan in 2006. Journal of Health and Welfare Statistics 2007, 54(13):44-52.

7. Kumar S, Quinn SC, Kim KH, Musa D, Hilyard KM, Freimuth VS: The Social Ecological Model as a Framework for Determinants of 2009 H1N1 Influenza Vaccine Uptake in the United States. Health Educ Behav 2012, 39(2):229-243.

8. Bone A, Guthmann JP, Nicolau J, Lévy-Bruhl D: Population and risk group uptake of H1N1 influenza vaccine in mainland France 2009-2010: results of a national vaccination campaign. Vaccine 2010, 28(51):8157-8161.

9. Maurer J, Uscher-Pines L, Harris KM: Perceived seriousness of seasonal and A (H1N1) influenzas, attitudes toward vaccination, and vaccine uptake among US adults: Does the source of information matter? Prev Med 2010, 51(2):185-187.

10. Yi S, Nonaka D, Nomoto M, Kobayashi J, Mizoue T: Predictors of the uptake of $A$ (H1N1) influenza vaccine: findings from a population-based longitudinal study in Tokyo. PLoS One 2011, 6(4):e18893.

11. Sypsa V, Livanios T, Psichogiou M, Malliori M, Tsiodras S, Nikolakopoulos I, A H: Public perceptions in relation to intention to receive pandemic influenzavaccination in a random population sample: evidence from a cross-sectional telephone survey. Euro Surveill 2009, 14(49):19437.

12. Schwarzinger M, Flicoteaux R, Cortarenoda S, Obadia Y, Moatti JP: Low acceptability of $\mathrm{A} / \mathrm{H} 1 \mathrm{~N} 1$ pandemic vaccination in French adult population: did public health policy fuel public dissonance? PLOS One 2010, 5(4):e10199.

13. Barriere J, Vanjak D, Kriegel I, Otto J, Peyrade F, Esteve M, Chamorey E: Acceptance of the $2009 \mathrm{~A}(\mathrm{H} 1 \mathrm{~N} 1)$ influenza vaccine among hospital workers in two French cancer centers. Vaccine 2010, 28(43):7030-7034. 
14. Hothersall EJ, de Bellis-Ayres $S$, Jordan R: Factors associated with uptake of pandemic influenza vaccine among general practitioners and practice nurses in Shropshire, UK. Prim Care Respir J 2012, 21(3):302-307.

15. Blank PR, Freiburghaus AU, Schwenkglenks M, Szucs TD: Trends in influenza vaccination coverage rates in the United Kingdom over six seasons from 2001-2 to 2006-7. Euro Surveill 2008, 13(43):19014.

16. Blank PR, Schwenkglenks M, Szucs TD: Influenza vaccination coverage rates in five European countries during season 2006/07 and trends over six consecutive seasons. BMC Publ Health 2008, 8:272.

17. Holm MV, Blank PR, Szucs TD: Trends in influenza vaccination coverage rates in Germany over five seasons from 2001 to 2006. BMC Infect Dis 2007, 7:144.

18. Ma X, He Z, Wang Y, Jiang L, Xu Y, Qian C, Sun R, Chen E, Hu Z, Zhou L, et al: Knowledge and attitudes of healthcare workers in Chinese intensive care units regarding 2009 H1N1 influenza pandemic. BMC Infect Dis 2011, 11:24

19. Gargano LM, Painter JE, Sales JM, Morfaw C, Jones LM, Murray D, Wingood GM, DiClemente RJ, Hughes JM: Seasonal and 2009 H1N1 influenza vaccine uptake, predictors of vaccination, and self-reported barriers to vaccination among secondary school teachers and staff. Hum Vaccin 2011, 7(1):89-95.

20. Akan H, Gurol Y, Izbirak G, Ozdatlı S, Yilmaz G, Vitrinel A, Hayran O: Knowledge and attitudes of university students toward pandemic influenza: a crosssectional study from Turkey. BMC Publ Health 2010, 10(1):413.

21. Esposito S, Bosis S, Pelucchi C, Tremolati E, Sabatini C, Semino M, Marchisio P, della Croce F, Principi N: Influenza vaccination among healthcare workers in a multidisciplinary University hospital in Italy. BMC Publ Health 2008, 8:422.

22. Hollmeyer HG, Hayden F, Poland G, Buchholz U: Influenza vaccination of health care workers in hospitals-a review of studies on attitudes and predictors. Vaccine 2009, 27(30):3935-3944.

23. Osterholm MT, Kelley NS, Sommer A, Belongia EA: Efficacy and effectiveness of influenza vaccines: a systematic review and metaanalysis. Lancet Infect Dis 2012, 12(1):36-44.

24. Jefferson T, Di Pietrantonj C, Rivetti A, Bawazeer GA, Al-Ansary LA, Ferroni E: Vaccines for preventing influenza in healthy adults. Cochrane Database Syst Rev 2010(7). doi:10.1002/14651858.CD001269.pub4.

25. Zaman K, Roy E, Arifeen SE, Rahman M, Raqib R, Wilson E, Omer SB, Shahid NS, Breiman RF, Steinhoff MC: Effectiveness of maternal influenza immunization in mothers and infants. N Engl J Med 2008, 359(15):1555-1564.

26. Crawford ND, Blaney S, Amesty S, Rivera AV, Turner AK, Ompad DC, Fuller CM: Individual- and neighborhood-level characteristics associated with support of in-pharmacy vaccination among ESAP-registered pharmacies: pharmacists' role in reducing racial/ethnic disparities in influenza vaccinations in New York City. J Urban Health 2011, 88(1):176-185.

27. Nowalk MP, Lin CJ, Toback SL, Rousculp MD, Eby C, Raymund M, Zimmerman RK: Improving influenza vaccination rates in the workplace: a randomized trial. Am J Prev Med 2010, 38(3):237-246.

28. Liao Q, Cowling BJ, Lam WW, Fielding R: Factors affecting intention to receive and self-reported receipt of 2009 pandemic (H1N1) vaccine in Hong Kong: a longitudinal study. PLoS One 2011, 6(3):e17713.

29. Lee JS, Kawakubo K: Influenza vaccination coverage in Japan. Lancet 2003, 362(9397):1767.

30. Lau JTF, Yeung NCY, Choi K, Cheng MYM, Tsui H, Griffiths S: Acceptability of $A / H 1 N 1$ vaccination during pandemic phase of influenza $A / H 1 N 1$ in Hong Kong: population based cross sectional survey. BMJ: British Medical Journal 2009, 339:b4164.

31. Hirota $Y$, Kaji M: History of influenza vaccination programs in Japan. Vaccine 2008, 26(50):6451-6454

doi:10.1186/1471-2458-13-647

Cite this article as: Iwasa and Wada: Reasons for and against receiving influenza vaccination in a working age population in Japan: a national cross-sectional study. BMC Public Health 2013 13:647.

\section{Submit your next manuscript to BioMed Central and take full advantage of:}

- Convenient online submission

- Thorough peer review

- No space constraints or color figure charges

- Immediate publication on acceptance

- Inclusion in PubMed, CAS, Scopus and Google Scholar

- Research which is freely available for redistribution

Submit your manuscript at www.biomedcentral.com/submit
Ciomed Central 